\title{
Early systemic-to-pulmonary artery shunt intervention in neonates with congenital heart disease
}

\author{
Matthew J. O'Connor, MD, ${ }^{a}$ Chitra Ravishankar, MD, ${ }^{\mathrm{a}}$ Jean A. Ballweg, MD, ${ }^{\mathrm{b}}$ Matthew J. Gillespie, MD, ${ }^{\mathrm{a}}$ \\ J. William Gaynor, MD, ${ }^{\mathrm{c}}$ Sarah Tabbutt, MD, PhD, ${ }^{\mathrm{d}}$ and Troy E. Dominguez, $\mathrm{MD}^{\mathrm{e}}$
}

Objective: To determine the incidence, risk factors, and outcomes after early, unplanned intervention on systemic-to-pulmonary artery shunts in neonates.

\begin{abstract}
Methods: We retrospectively studied all neonates undergoing systemic-to-pulmonary artery shunt placement at The Children's Hospital of Philadelphia between September 1, 2002, and May 1, 2005. Patients requiring transcatheter or surgical systemic-to-pulmonary artery shunt intervention before discharge were compared with those not undergoing shunt intervention.
\end{abstract}

\begin{abstract}
Results: A total of 206 patients underwent shunt placement. Diagnoses included hypoplastic left heart syndrome $(62.1 \%)$, pulmonary atresia $(15 \%)$, tricuspid atresia $(4.9 \%)$, tetralogy of Fallot $(2.4 \%)$, and other lesions with obstruction to systemic $(10.7 \%)$ or pulmonary blood flow $(4.9 \%)$. Twenty-one interventions occurred in 20 patients $(9.7 \%)$. Risk factors for intervention included heterotaxy syndrome $(P=.04)$, congenital abnormality $(P=.04)$, and a trend toward lower birthweight. In patients with a modified Blalock-Taussig shunt, similar risk factors were identified and the incidence of intervention decreased with increasing shunt size. In-hospital mortality was $30 \%(6 / 20)$ for the cases and $8.1 \%(15 / 186)$ for the nonintervention group $(P=.02)$. Longterm survival was significantly lower in patients requiring intervention $(P=.002)$. This group also had a higher incidence of infections $(P<.001)$ and extracorporeal membrane oxygenation $(P<.001)$, and longer hospital stay $(P=.001)$.
\end{abstract}

Conclusions: In neonates undergoing systemic-to-pulmonary artery shunt placement, approximately $10 \%$ underwent shunt intervention before discharge. Some factors, such as low birthweight, shunt size, noncardiac congenital abnormalities, and heterotaxy syndrome, may help identify patients at risk. Patients undergoing intervention experienced increased morbidity and mortality. (J Thorac Cardiovasc Surg 2011;142:106-12)

The systemic-to-pulmonary artery (S-PA) shunt is widely used in the surgical palliation of various forms of congenital heart disease (CHD). After placement, maintenance of shunt patency and freedom from mechanical distortion of the shunt and pulmonary arteries are imperative because pulmonary blood flow is exclusively shunt-dependent in the absence of native or collateral pulmonary blood flow.

Despite improvements in operative mortality in recent decades ${ }^{1}$ that parallel increased survival in children with CHD, patients with shunt-dependent pulmonary blood flow continue to experience significant early and late mortality. ${ }^{2-5}$ In particular, out-of-hospital death after shunt

From the Division of Cardiology, ${ }^{\text {a }}$ Department of Pediatrics, Department of Anesthesia and Critical Care Medicine, ${ }^{b}$ and Department of Cardiothoracic Surgery, ${ }^{\mathrm{c}}$ The Children's Hospital of Philadelphia, Philadelphia, Pa; Divisions of Cardiology and Critical Care Medicine, ${ }^{\mathrm{d}}$ Department of Pediatrics, University of California San Francisco, San Francisco, Calif; and Cardiorespiratory Unit, ${ }^{\mathrm{e}}$ Great Ormond Street Hospital for Children, London, United Kingdom.

Disclosures: Authors have nothing to disclose with regard to commercial support.

Received for publication June 29, 2010; revisions received Sept 25, 2010; accepted for publication Oct 17, 2010; available ahead of print Jan 27, 2011.

Address for reprints: Matthew J. O'Connor, MD, Division of Cardiology, The Children's Hospital of Philadelphia, 34th St and Civic Center Blvd, Philadelphia, PA 19104-4399 (E-mail: oconnorm@email.chop.edu)

$0022-5223 / \$ 36.00$

Copyright (c) 2011 by The American Association for Thoracic Surgery doi:10.1016/j.jtcvs.2010.10.033 placement and before further surgical interventions (interstage mortality) continues to occur in $10 \%$ to $15 \%$ of infants. ${ }^{2,3}$ Postoperative mortality has been ascribed to many potential factors, with acute or chronic shunt occlusion from shunt thrombosis, shunt stenosis, or downstream pulmonary artery distortion likely playing a large role in postoperative attrition. Measures that have been proposed to detect or prevent events leading to interstage mortality include home monitoring with pulse oximetry, ${ }^{6}$ postoperative heparin administration, ${ }^{7}$ and aspirin. ${ }^{8}$ A recent prospective multicenter, multinational trial demonstrated that postoperative aspirin in patients with S-PA shunts decreased the risk of shunt thrombosis and death. ${ }^{4}$

Morbidity and mortality related to S-PA shunts may be in part affected by shunt type. In children with hypoplastic left heart syndrome (HLHS) undergoing stage I palliation, the relative incidence of shunt intervention between modified Blalock-Taussig shunts (mBTS) and right ventricleto-pulmonary artery (RV-PA) shunts has been studied extensively. Previous work from our center ${ }^{9,10}$ demonstrated an increased incidence of unplanned shunt interventions in patients receiving an RV-PA shunt. Similarly, in the randomized, multicenter single ventricle reconstruction trial comparing outcomes in children with HLHS and variants 


\section{Abbreviations and Acronyms \\ BUN = blood urea nitrogen \\ $\mathrm{CHD}=$ congenital heart disease \\ $\mathrm{ECMO}=$ extracorporeal membrane oxygenation \\ HLHS = hypoplastic left heart syndrome \\ mBTS $=$ modified Blalock-Taussig shunt \\ RV-PA $=$ right ventricle-to-pulmonary artery \\ $\mathrm{S}-\mathrm{PA}=$ systemic-to-pulmonary artery}

according to the type of S-PA shunt (mBTS vs RV-PA shunt) placed at the Norwood procedure, the incidence of unplanned cardiovascular interventions in the first 12 months after trial enrollment was higher in the group receiving an RV-PA shunt. Early survival was greater with the RV-PA shunt group, but survival between groups was not significantly different in late follow-up. ${ }^{11}$

Although many cases of S-PA shunt dysfunction only come to clinical attention after hospital discharge and thus fall into the interstage period, we have noted that a sizeable proportion of patients palliated with S-PA shunts manifest evidence of shunt dysfunction during their initial hospitalization. The incidence of and risk factors for such "early" S-PA shunt dysfunction in CHD have not been well defined. The primary purpose of this study was to describe the incidence of shunt dysfunction and identify risk factors for early surgical or transcatheter shunt intervention in patients with CHD palliated with S-PA shunts.

\section{PATIENTS AND METHODS}

After institutional review board approval and waiver of informed consent, a retrospective cohort study of all neonates ( $\leq 30$ days of age) undergoing S-PA shunt placement at The Children's Hospital of Philadelphia between September 1, 2002, and May 1, 2005, was performed $(\mathrm{n}=206)$. For the purposes of this study, S-PA shunts were defined as one of the following surgically placed connections between the systemic and pulmonary circulations: mBTS, central shunts, and RV-PA shunts as part of the Norwood procedure for HLHS and variants. The patient population was identified through review of the cardiac intensive care unit, cardiology, and surgical databases. We obtained information regarding the postoperative course, morbidity, and mortality by review of the hospital medical record, operative reports, cardiac catheterization reports, echocardiogram reports, and contact with referring physicians.

Four surgeons were active during the time period of this study. For patients with HLHS and other single ventricle lesions with obstructed systemic blood flow undergoing stage I palliation, operative technique and general institutional standards of postoperative care have been described. ${ }^{9}$ The type of shunt placed was at the discretion of the attending surgeon. The ductus arteriosus was uniformly ligated in lesions with ductal-dependent systemic blood flow, and with few exceptions was ligated in lesions with ductal-dependent pulmonary blood flow. Patients evaluated in this study were not enrolled in the multicenter single ventricle reconstruction trial. ${ }^{11,12}$ After initial shunt placement, patients undergoing a separately performed surgical or transcatheter shunt intervention before hospital discharge were identified (intervention group) and compared with neonates undergoing S-PA shunt placement during the same time period who did not undergo in-hospital intervention (nonintervention group). $\mathrm{Pa}$ tients transferred from The Children's Hospital of Philadelphia to another inpatient medical facility who returned for intervention were included in the intervention group. We excluded patients who underwent intraoperative shunt revision during the initial shunt procedure or shunt intervention after hospital discharge, as well as those with suspected shunt dysfunction who did not undergo an intervention procedure.

All patients were characterized by gender, gestational age, birthweight, presence of significant noncardiac congenital abnormalities (including identified genetic syndromes), presence of heterotaxy syndrome, underlying cardiac diagnosis, and age at S-PA shunt placement. Prematurity was defined categorically as a gestational age at birth of less than 37 completed weeks of gestation. Low birthweight was defined categorically as less than $2.5 \mathrm{~kg}$. All patients classified as having noncardiac congenital abnormalities underwent evaluation by a geneticist. Cardiac diagnoses were obtained by review of echocardiogram, cardiac catheterization, and operative reports. In cases of disagreement, the diagnosis listed in the operative report was used. Cardiac lesions were grouped according to shared anatomic and physiologic characteristics: (1) HLHS and variants (critical systemic ventricular outflow obstruction not amenable to biventricular repair), (2) tricuspid atresia, (3) pulmonary atresia and variants (including pulmonary atresia with intact ventricular septum), (4) tetralogy of Fallot (including tetralogy of Fallot with pulmonary atresia), and (5) other functional single ventricle lesions with obstruction to systemic or pulmonary blood flow.

Intra- and postoperative variables related to S-PA shunt placement were characterized, including shunt type and size, use of cardiopulmonary bypass, extracorporeal membrane oxygenation (ECMO) use, intravascular volume status (as assessed by highest daily blood urea nitrogen [BUN]), number of bloodstream or surgical wound infections, use of low-dose $(10-20 \mathrm{U} / \mathrm{kg} / \mathrm{h})$ heparin infusion in the immediate ( $\leq 48$ hours) postoperative period, presence of antegrade pulmonary blood flow after shunt placement, duration of hospital stay, and mortality. Mortality was classified as early (occurring $\leq 30$ days of S-PA shunt placement or during the same hospitalization) or late (>30 days after S-PA shunt placement and after discharge home). Infections were defined as distinct clinical episodes requiring antibiotics along with positive blood or surgical wound cultures.

During the time period of this study, low-dose heparin infusion was not used routinely. Antiplatelet therapy was initiated postoperatively at the discretion of the attending staff. For patients requiring intervention, timing of intervention, type of intervention, mechanism of shunt dysfunction, and use of anticoagulant or antiplatelet therapy within the 3 days before shunt intervention were recorded. The mechanism of shunt dysfunction leading to intervention was ascertained by review of angiograms, cardiac catheterization, or operative reports, and was classified as secondary to thrombosis, mechanical distortion of the shunt or pulmonary arteries, a combination of thrombosis and distortion, or indeterminate.

Data are reported as mean \pm standard deviation for normally distributed data or median (range) otherwise. Categoric data are presented as n (\%). Comparisons between the intervention and nonintervention groups using continuous variables were performed using the Student $t$ test for normally distributed variables; otherwise, the Mann-Whitney $U$ test was used. Comparisons between categoric variables were performed using Fisher's exact or chi-square test, as appropriate. Logistic regression was also performed to evaluate the association between identified risk factors and shunt intervention. Assessments of the trend in proportions across ordered groups, used for the analysis of shunt size and intervention rates, were made using an extension to the Wilcoxon rank-sum test (STATA command "nptrend"). The association between birthweight and S-PA shunt size was assessed using Spearman's rank correlation. Survival curves were generated using the Kaplan-Meier method, and comparison of survival curves between the intervention and nonintervention groups was performed using the log-rank test. For the survival analysis, follow-up time was calculated from the date of surgery to the date of death or the last date the patient was known 
TABLE 1. Diagnoses $(n=206)$

\begin{tabular}{lc}
\hline \multicolumn{1}{c}{ Diagnosis } & No. $(\%$ of total) \\
\hline Hypoplastic left heart syndrome and variants & $128(62.1)$ \\
Pulmonary atresia and variants & $31(15.0)$ \\
Tricuspid atresia & $10(4.9)$ \\
Tetralogy of Fallot & $5(2.4)$ \\
Other lesions with obstructed SBF & $22(10.7)$ \\
Other lesions with obstructed PBF & $10(4.9)$ \\
\hline$S B F$, Systemic blood flow; $P B F$, pulmonary blood flow.
\end{tabular}

to be alive. All data were analyzed using STATA 10.0 software (STATA Corporation, College Station, Tex).

\section{RESULTS \\ Patient Demographics}

During the study period, 206 patients underwent S-PA shunt placement at a median 3.0 days of age (0-29 days); $64.1 \%(132 / 206)$ were male. Cardiac diagnoses and types of shunts placed are shown in Tables 1 and 2, respectively. Mean birthweight was $3.0 \pm 0.6 \mathrm{~kg}$, and $18.9 \%(39 / 206)$ had a birthweight less than $2.5 \mathrm{~kg}$; $13.6 \%(28 / 206)$ were premature.

Noncardiac congenital abnormalities, including genetic syndromes and heterotaxy syndrome, were identified in $21.4 \%(44 / 206)$ of the entire group. The most commonly encountered specific noncardiac congenital syndromes aside from heterotaxy included Turner syndrome ( 3 patients), tracheoesophageal fistula (3 patients), hemifacial microsomia (3 patients), VACTERL association (2 patients), and trisomy 21 (2 patients). Heterotaxy syndrome was present in 15 patients $(7.3 \%)$, with 8 demonstrating the asplenia type and 7 demonstrating the polysplenia type of heterotaxy. Totally anomalous pulmonary venous connection was present in 4 of the patients with heterotaxy, with 1 demonstrating obstructed pulmonary venous connections before S-PA shunt placement.

\section{Shunt Interventions}

A total of 21 S-PA shunt interventions occurred in 9.7\% of patients $(20 / 206)$, with the majority $(75 \%)$ being male (Table 3). One patient underwent 2 interventions; the first at 28 days and the second at 52 days after shunt placement. Intervention occurred within 24 hours of S-PA shunt placement in $20 \%(4 / 20)$; the remainder of interventions occurred at a median of 12 (4-52) days after S-PA shunt

TABLE 2. Types of shunts placed $(n=206)$

\begin{tabular}{lc}
\hline \multicolumn{1}{c}{ Shunt type } & No. $(\%)$ \\
\hline mBTS & $55(26.7)$ \\
Central & $5(2.4)$ \\
Stage I palliation with mBTS & $90(43.7)$ \\
Stage I palliation with RV-PA shunt & $56(27.2)$ \\
\hline$m B T S$, Modified Blalock-Taussig shunt; $R V-P A$, right ventricle to pulmonary artery.
\end{tabular}

placement. Surgical shunt revisions comprised $62 \%$ of interventions (13/21). Cardiac catheterization was performed in $86 \%$ of interventions (18/21) for the purposes of diagnosis; in the remainder, surgical shunt revision was performed without antecedent catheterization. The mechanism of shunt dysfunction was shunt thrombosis in 33\% (7/21), shunt distortion in $38 \%(8 / 21)$, a combination of thrombosis and distortion in $19 \%(4 / 21)$, and indeterminate in $10 \%$ $(2 / 21)$ of interventions. Urgent intervention occurred in $45 \%$ of patients $(9 / 20)$. The onset of shunt dysfunction was temporally associated with cardiac arrest in $15 \%$ of patients (3/20), and ECMO was necessary in $30 \%$ of patients $(6 / 20)$.

Postoperative low-dose heparin was used in $10.2 \%$ of patients $(21 / 206)$ in the entire cohort. For patients undergoing intervention, $35 \%(7 / 20)$ were receiving no anticoagulant or antiplatelet therapy within the 3 days preceding shunt intervention. Infection was present in $30 \%$ of patients $(6 / 20)$ at the time of intervention. The highest BUN values measured in each of the 4 days preceding shunt intervention were recorded and averaged for each patient; the median of this aggregate BUN was $13.8(3.5-43.8) \mathrm{mg} / \mathrm{dL}(4.9$ [1.3-15.8] $\mathrm{mmol} / \mathrm{L})$.

\section{Risk Factors for Shunt Intervention}

To evaluate risk factors for early S-PA shunt intervention, intervention, and nonintervention groups were compared for relevant demographic and clinical variables before shunt placement. A univariate analysis of factors associated with shunt intervention is shown in Table 4. S-PA shunt size was modestly correlated with weight for the entire group $(r=0.28, P<.001)$; there was a stronger correlation between shunt size and weight in those who received an mBTS $(r=0.65, P<.001)$.

In the subgroup of patients who received an mBTS $(\mathrm{n}=145)$, risk factors associated with intervention were similar to those found in the entire group. The rate of intervention in the mBTS group was $7.6 \%$ (11/145). Risk factors included trends in association with birthweight less than 2.5 $\mathrm{kg}(14.9 \%$ [20/134] in the nonintervention group with mBTS vs $36.4 \%$ [4/11] in the intervention group with mBTS, $P=.09$ ) and in those patients with a noncardiac congenital abnormality $(20.2 \%$ [27/134] in the nonintervention group with mBTS vs $45.5 \%$ [5/11] in the intervention group with $\mathrm{mBTS}, P=.07$ ). A combined variable representing those patients with a noncardiac congenital abnormality or birthweight less than $2.5 \mathrm{~kg}$ was significantly associated with an intervention $(\mathrm{OR}=3.6 ; 95 \% \mathrm{CI}$, $1.4-9.2 ; P=.009$ ). The rate of intervention also significantly decreased with increasing shunt size in patients with an $\operatorname{mBTS}(P=.01$, Table 4$)$. A similar analysis in the patients who received an RV-PA shunt was limited by the smaller sample size $(\mathrm{n}=56)$ and the predominant use of a $5.0-\mathrm{mm}$ shunt $(88 \%)$ in this group. 
TABLE 3. Characteristics of patients undergoing intervention $(n=20)$

\begin{tabular}{|c|c|c|c|c|c|c|c|c|c|c|c|}
\hline ID & Diagnosis & Heterotaxy & $\begin{array}{c}\text { Shunt } \\
\text { procedure }\end{array}$ & $\begin{array}{c}\text { Intervention } \\
\text { date* }\end{array}$ & $\begin{array}{c}\text { Cardiac } \\
\text { arrest }\end{array}$ & ECMO & $\begin{array}{c}\text { Mode of } \\
\text { intervention }\end{array}$ & $\begin{array}{c}\text { Cause of shunt } \\
\text { dysfunction }\end{array}$ & $\begin{array}{l}\text { Anticoagulant/platelet } \\
\text { therapy within } 3 \text { days } \\
\text { of intervention }\end{array}$ & $\begin{array}{c}\text { Patient } \\
\text { status }\end{array}$ & $\begin{array}{c}\text { Timing of } \\
\text { death }\end{array}$ \\
\hline 1 & HLHS & + & S1 RV-PA & 1 & & & Surgical & Distortion & None & Deceased & Interstage \\
\hline 2 & Truncus arteriosus, UAVC & + & S1 mBTS & 9 & & + & Transcatheter & Distortion & Heparin & Deceased & In-hospital \\
\hline 3 & HLHS & & S1 RV-PA & 11 & & & Transcatheter & Distortion & ASA & Alive & \\
\hline 4 & PA/IVS & & mBTS & 0 & & & Surgical & Indeterminate $\ddagger$ & None & Alive & \\
\hline 5 & HLHS & & S1 RV-PA & 9 & & & Surgical & Thrombosis and distortion & Heparin & Deceased & In-hospital \\
\hline 6 & HLHS & & $\mathrm{S} 1 \mathrm{mBTS}$ & 15 & & & Surgical & Thrombosis & Heparin & Deceased & Post-SCPA \\
\hline 7 & TOF & & mBTS & 5 & & & Transcatheter & Thrombosis & ASA & Deceased & In-hospital \\
\hline 8 & HLHS & + & S1 mBTS & 11 & & & Surgical & Distortion & ASA & Alive & \\
\hline 9 & HLHS & & S1 RV-PA & 46 & & & Transcatheter & Distortion & ASA & Alive & \\
\hline 10 & HLHS & & S1 RV-PA & 51 & & & Transcatheter & Thrombosis and distortion & ASA & Deceased & Interstage \\
\hline 11 & DILV & & S1 Central & 4 & & & Transcatheter & Thrombosis and distortion & None & Alive & \\
\hline 12 & HLHS & & $\mathrm{S} 1 \mathrm{mBTS}$ & 18 & + & + & Surgical & Thrombosis and distortion & Enoxaparin & Deceased & Post-SCPA \\
\hline 13 & D-TGA with IAA & & S1 mBTS & 11 & + & + & Surgical & Thrombosis & ASA & Alive & \\
\hline 14 & HLHS & & S1 RV-PA & 12 & & & Transcatheter & Distortion & Heparin & Alive & \\
\hline 15 & HLHS & & S1 RV-PA & 17 & & & Surgical & Indeterminate $\oint$ & None & Deceased & Post-SCPA \\
\hline 16 & HLHS & & $\mathrm{S} 1 \mathrm{mBTS}$ & 0 & + & + & Surgical & Thrombosis & None & Deceased & Interstage \\
\hline 17 & HLHS & & S1 RV-PA & 5 & & & Surgical & Distortion & None & Deceased & In-hospital \\
\hline 18 & HLHS & + & S1 mBTS & 1 & & + & Surgical & Thrombosis & None & Deceased & In-hospital \\
\hline $19 \dagger$ & DILV & & $\mathrm{S} 1 \mathrm{mBTS}$ & 28 & & + & Surgical & Thrombosis & ASA & Deceased & In-hospital \\
\hline 20 & PA/IVS & & mBTS & 13 & & & Surgical & Distortion & ASA & Alive & \\
\hline
\end{tabular}

UAVC, Unbalanced atrioventricular canal; $P A / I V S$, pulmonary atresia with intact ventricular septum; TOF, tetralogy of Fallot; $D I L V$, double-inlet left ventricle; $D$-TGA, D-loop transposition of the great vessels; IAA, interrupted aortic E arch; $S 1$, stage I palliation; $S C P A$, superior cavopulmonary anastomosis; $m B T S$, modified Blalock-Taussig shunt; $R V$-PA, right ventricle to pulmonary artery; $E C M O$, extracorporeal membrane oxygenation; $A S A$, acetyl salicylic acid.

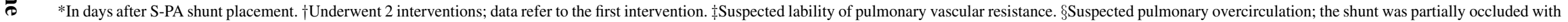
A a band.

를 
TABLE 4. Comparisons of patients undergoing intervention, compared with nonintervention group for preoperative, operative, and postoperative variables

\begin{tabular}{|c|c|c|c|}
\hline & $\begin{array}{c}\text { Nonintervention } \\
\quad(\mathbf{n}=\mathbf{1 8 6}) \\
\end{array}$ & $\begin{array}{c}\text { Intervention } \\
\quad(\mathbf{n}=\mathbf{2 0})\end{array}$ & $\begin{array}{c}P \\
\text { value }\end{array}$ \\
\hline \multicolumn{4}{|l|}{ Preoperative variables } \\
\hline Birthweight (kg) & $3.1 \pm 0.6$ & $2.8 \pm 0.7$ & .21 \\
\hline Birthweight $<2.5 \mathrm{~kg}$ & $33(18)$ & $6(30)$ & .18 \\
\hline Age at S-PA shunt (d) & $3.5(0-29)$ & $3.0(1-18)$ & .23 \\
\hline Premature & $24(13)$ & $4(20)$ & .49 \\
\hline Female & $69(37)$ & $5(25)$ & .34 \\
\hline Diagnosis & & & .43 \\
\hline HLHS & $115(62)$ & $13(65)$ & \\
\hline Pulmonary atresia & $29(16)$ & $2(10)$ & \\
\hline Tricuspid atresia & $10(5)$ & $0(0)$ & \\
\hline Obstructed SBF & $18(10)$ & $4(20)$ & \\
\hline Obstructed PBF & $10(5)$ & $0(0)$ & \\
\hline TOF & $4(2)$ & $1(5)$ & \\
\hline Heterotaxy syndrome & $11(6)$ & $4(20)$ & .04 \\
\hline $\begin{array}{l}\text { Congenital abnormality } \\
\text { (including heterotaxy) }\end{array}$ & $36(19)$ & $8(40)$ & .04 \\
\hline \multicolumn{4}{|l|}{ Operative variables } \\
\hline Shunt type & & & .27 \\
\hline $\mathrm{S} 1 \mathrm{mBTS}$ & $82(44)$ & $8(40)$ & \\
\hline S1 RV-PA & $48(26)$ & $8(40)$ & \\
\hline mBTS & $52(28)$ & $3(15)$ & \\
\hline Central & $4(2)$ & $1(5)$ & \\
\hline Shunt size (mBTS only) & $\mathrm{n}=134$ & $\mathrm{n}=11$ & .03 \\
\hline $3.0 \mathrm{~mm}$ & $0(0)$ & $1(9)$ & $.01 \dagger$ \\
\hline $3.5 \mathrm{~mm}$ & $63(47)$ & $8(73)$ & \\
\hline $4.0 \mathrm{~mm}$ & $68(51)$ & $2(18)$ & \\
\hline $5.0 \mathrm{~mm}$ & $3(2)$ & $0(0)$ & \\
\hline Use of CPB & $18(10)$ & $2(10)$ & .99 \\
\hline Pulmonary arterioplasty & $16(9)$ & $0(0)$ & .38 \\
\hline \multicolumn{4}{|l|}{ Postoperative variables } \\
\hline $\begin{array}{l}\text { Low-dose postoperative } \\
\text { heparin* }\end{array}$ & $20(11)$ & $1(6)$ & .35 \\
\hline Native PBF & $21(11)$ & $1(5)$ & .70 \\
\hline
\end{tabular}

\section{Outcomes}

The clinical characteristics and outcomes of patients undergoing early S-PA shunt intervention are summarized in Table 3. The in-hospital mortality was significantly higher in the intervention group compared with the nonintervention group $(30 \% \quad[6 / 20]$ vs $8.1 \% \quad[15 / 186]$, $P=.02)$. The median duration of follow-up from S-PA shunt placement was $5.0(0-7.0)$ years, with the majority of patients having complete follow-up through September 1, 2009 (93.2\% [192/206]). The survival curves were significantly different in the patients undergoing intervention compared with those who did not $(P=.002$, Figure 1$)$. At

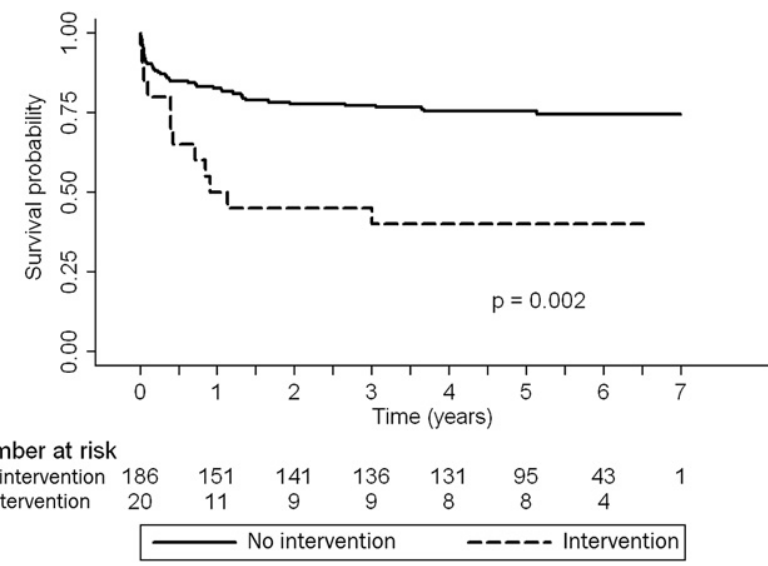

FIGURE 1. Kaplan-Meier survival for cohort according to intervention status. Kaplan-Meier survival curves for nonintervention (solid line) and intervention (dashed line) groups, with number remaining at risk yearly between 0 and 7 years after shunt placement shown at bottom. $P$ value shown is for comparison of overall survival between groups using logrank test.

1- and 5-year follow-up, median survival was 50.0\% $(27.1 \%-69.2 \%)$ and $41.2 \%(19.3 \%-60.1 \%)$, respectively, in the patients who required intervention compared with $83.2 \%(77.0-88.0 \%)$ and $76.8 \%(70.0-80.2 \%)$, respectively, in those who did not. Of the 12 deaths in the intervention group, $50 \%(6 / 12)$ occurred during the hospitalization for shunt placement, 25\% (3/12) occurred after hospital discharge, and $25 \%(3 / 12)$ occurred after stage II palliation. Of the 46 deaths in the nonintervention group, 32.6\% (15/46) occurred during the hospitalization for shunt placement, $41.3 \%$ (19/46) occurred after hospital discharge, and $26.1 \%$ (12/46) occurred after stage II palliation. Potentially confounding factors, such as gestational age, cardiac diagnosis, shunt type, year of surgery, and postoperative heparin use, were not significantly different between groups.

\section{Morbidity}

Greater morbidity was observed in the intervention group. Patients undergoing shunt intervention had a greater incidence of bloodstream or surgical wound infections after shunt placement $(60 \% \quad[12 / 20]$ vs $17.7 \% \quad[33 / 186]$, $P<.001)$, longer median hospital length of stay $(35$ [6-421] days vs 16 [3-386] days, $P=.001$ for all patients; 36 [16-134] days vs 16 [4-386] days for hospital survivors only, $P=.002)$, and need for ECMO after shunt placement $(30 \%[6 / 20]$ vs $5.4 \%$ [10/186], $P<.001)$ (Table 5).

\section{DISCUSSION}

Our results demonstrate that S-PA shunt dysfunction is a complex clinical entity with multiple potential causes, variable clinical presentation, and significant morbidity and mortality. In-hospital shunt intervention occurred in 
TABLE 5. Comparisons of patients undergoing intervention, compared with nonintervention group with respect to morbidity after systemic-to-pulmonary artery shunt placement

\begin{tabular}{lccc}
\hline & $\begin{array}{c}\text { Nonintervention } \\
(\mathbf{n}=\mathbf{1 8 6})\end{array}$ & $\begin{array}{c}\text { Intervention } \\
(\mathbf{n}=\mathbf{2 0})\end{array}$ & $\begin{array}{c}\boldsymbol{P} \\
\text { value }\end{array}$ \\
\hline $\begin{array}{l}\text { Presence of infection } \\
\text { No. of patients with }\end{array}$ & $33(18)$ & $12(60)$ & $<.001$ \\
$\quad$ & & & \\
$\quad$ infection & $26(14)$ & $3(15)$ & $<.001$ \\
$\quad$ infections & $5(3)$ & $4(20)$ & \\
ECMO use & $2(1)$ & $5(25)$ & \\
Hospital length of stay (d) & $10(5)$ & $6(30)$ & $<.001$ \\
Hospital length of stay, & $16(3-386)$ & $35(6-421)$ & .001 \\
$\quad 16(4-386)$ & $36(16-134)$ & .002 \\
\hline hospital survivors only (d) & & & \\
\hline $\begin{array}{l}\text { (\%), as appropriate. } \\
\text { \% }\end{array}$ & & & \\
\end{tabular}

$9.7 \%$, with a very high mortality $(60 \%$ at 5 years $)$ compared with contemporary controls. Our finding of continued late attrition in early survivors of S-PA shunt intervention identifies this as a very high-risk subgroup of patients, as evidenced by the fact that $50 \%$ of the deaths in the intervention group died unexpectedly at home or after stage II palliation. In addition, the intervention group also demonstrated significantly increased measures of morbidity compared with the nonintervention group, with an increased incidence of infections, hospital length of stay, and need for ECMO.

Risk factors for early shunt intervention included the presence of noncardiac congenital abnormalities (including heterotaxy syndrome) with a trend toward a higher rate of intervention in low birthweight infants. The rate of early shunt intervention decreased with increasing shunt size in patients with an mBTS. Because the use of smaller size shunts was correlated with birthweight, this may explain the trend toward a higher rate of intervention in low birthweight infants. Specifically, in patients with either a low birthweight or congenital abnormality, the risk of intervention was increased significantly in patients with an mBTS. Unfortunately, given the relatively infrequent occurrence of early shunt intervention, our sample size precludes multivariable analysis. An association between genetic syndromes and pulmonary artery hypoplasia in patients with tetralogy of Fallot has been reported ${ }^{13}$; the higher incidence of early shunt intervention in patients with noncardiac syndromes in this study could be explained in part by anatomic abnormalities of the pulmonary arterial circulation.

Heterotaxy is recognized to represent one of the highestrisk subgroups of CHD. ${ }^{14}$ Patients with heterotaxy experience mortality out of proportion to other patients with CHD. ${ }^{15,16}$ Much of the burden of mortality may be related to obstructed pulmonary venous return, ${ }^{14}$ although mortality may be improving in the current era for patients with heterotaxy, both those with univentricular ${ }^{17}$ and biven$\operatorname{tricular}^{18}$ anatomy. In our series, despite a low incidence of totally anomalous pulmonary venous connection, patients with heterotaxy comprised approximately $20 \%$ of patients undergoing intervention and the presence of heterotaxy was a risk factor for early shunt intervention. Our findings continue to provide supportive evidence that patients with heterotaxy remain a high-risk group, even in the absence of pulmonary venous abnormalities.

Although the study design prevented identification of infection as a risk factor for intervention, the fact that $30 \%$ of intervention patients were being treated for a culturepositive bacterial bloodstream or surgical wound infection at the time of intervention is notable. The link between bacterial infections and prothrombotic states is well established $^{19-21}$; patients with S-PA shunts and intercurrent infection warrant particularly close surveillance because infection may cause an occult prothrombotic state, thereby increasing the risk of shunt thrombosis.

At present, low-dose heparin is used frequently in the postoperative period to prevent shunt dysfunction. However, during the study period, postoperative heparin prophylaxis was less commonly used, and we did not find a relationship between the use of low-dose heparin infusions and the incidence of shunt intervention. Our low rate of prophylaxis combined with the low rate of intervention may contribute to an inability to detect a significant association. Other agents, such as clopidogrel, are actively being studied for thromboprophylaxis in children with S-PA shunts ${ }^{22}$ as additive therapy given the continued occurrence of shunt thrombosis with aspirin. Dehydration may to contribute to acute shunt thrombosis; however, the median preintervention BUN of patients, used as a marker of intravascular volume status, was not abnormally elevated. This may be related to the inpatient status of this population, in whom volume status and diuretic administration were carefully monitored.

\section{Limitations}

Our study has several limitations. Although we attempted to determine the cause of shunt malfunction by review of catheterization and surgical reports, pathologic analysis of the shunt was not performed, and retrospective analysis cannot determine the cause of dysfunction with certainty. We have likely underestimated the true incidence of shunt thrombosis or distortion by not capturing cases that resolved spontaneously, resolved after medical maneuvers in the intensive care unit, occurred after hospital discharge, or resulted in mortality before undergoing diagnostic testing. RV-PA shunts placed as part of the Norwood procedure for the palliation of HLHS may represent a different risk profile for intervention than mBTS. In our study, the rate of early shunt intervention was approximately twice as high in the RV-PA shunt group compared with the mBTS group $(14.3 \%$ vs $7.6 \%)$, but this finding was not statistically significant. A larger sample size would be necessary 
to better understand these differences and identify risk factors for this group because they comprised only one third of our patient population.

\section{CONCLUSIONS}

Approximately $10 \%$ of neonates undergoing S-PA shunt placement experienced early shunt dysfunction requiring surgical or transcatheter intervention before discharge. Some factors, such as low birthweight, shunt size, and noncardiac congenital abnormalities, may help identify patients at risk. The intervention group had a more complicated postoperative course with greater mortality. These patients remain at risk for late mortality; therefore, continued close surveillance of these patients is necessary.

The authors acknowledge Susan C. Nicolson, MD, Gil Wernovsky, MD, Peter J. Gruber, MD, PhD, and Thomas L. Spray, MD, for clinical care of the patients and critical review of earlier versions of this article.

\section{References}

1. Williams JA, Bansal AK, Kim BJ, Nwakanma LU, Patel ND, Seth AK, et al. Two thousand Blalock-Taussig shunts: a six-decade experience. Ann Thorac Surg. 2007;84:2070-5.

2. Fenton KN, Siewers RD, Rebovich B, Pigula FA. Interim mortality in infants with systemic-to-pulmonary artery shunts. Ann Thorac Surg. 2003;76:152-6.

3. Hehir DA, Dominguez TE, Ballweg JA, Ravishankar C, Marino BS, Bird GL, et al. Risk factors for interstage death after stage 1 reconstruction of hypoplastic left heart syndrome and variants. J Thorac Cardiovasc Surg. 2008;136:94-9.

4. Li JS, Yow E, Berezny KY, Rhodes JF, Bokesch PM, Charpie JR, et al. Clinical outcomes of palliative surgery including a systemic-to-pulmonary artery shunt in infants with cyanotic congenital heart disease: does aspirin make a difference? Circulation. 2007;116:293-7.

5. Mahle WT, Spray TL, Gaynor JW, Clark BJ. Unexpected death after reconstructive surgery for hypoplastic left heart syndrome. Ann Thorac Surg. 2001;71:61-5.

6. Ghanayem NS, Hoffman GM, Mussatto KA, Cava JR, Frommelt PC, Rudd NA, et al. Home surveillance program prevents interstage mortality after the Norwood procedure. J Thorac Cardiovasc Surg. 2003;126:1367-75.

7. Mullen JC, Lemermeyer G, Bentley MJ. Modified Blalock-Taussig shunts: to heparinize or not to heparinize? Can J Cardiol. 1996;12:645-7.
8. Al Jubair KA, Al Fagih MR, Al Jarallah AS, Al Yousef S, Ali Khan MA, Ashmeg A, et al. Results of 546 Blalock-Taussig shunts performed in 478 patients. Cardiol Young. 1998;8:486-90.

9. Tabbutt S, Dominguez TE, Ravishankar C, Marino BS, Gruber PJ, Wernovsky G, et al. Outcomes after the stage I reconstruction comparing the right ventricular to pulmonary artery conduit with the modified Blalock-Taussig shunt. Ann Thorac Surg. 2005;80:1582-90.

10. Ballweg JA, Dominguez TE, Ravishankar C, Kreutzer J, Marino BS, Bird GL, et al. A contemporary comparison of the effect of shunt type in hypoplastic left heart syndrome on the hemodynamics and outcome at stage 2 reconstruction. J Thorac Cardiovasc Surg. 2007;134:297-303.

11. Ohye RG, Sleeper LA, Mahony L, Newburger JW, Pearson GD, Lu M, et al. Comparison of shunt types in the Norwood procedure for single-ventricle lesions. N Engl J Med. 2010;362:1980-92.

12. Ohye RG, Gaynor JW, Ghanayem NS, Goldberg CS, Laussen PC, Frommelt PC, et al. Design and rationale of a randomized trial comparing the Blalock-Taussig and right ventricle-pulmonary artery shunts in the Norwood procedure. $J$ Thorac Cardiovasc Surg. 2008;136:968-75.

13. Michielon G, Marino B, Formigari R, Gargiulo G, Picchio F, Digilio MC, et al. Genetic syndromes and outcome after surgical correction of tetralogy of Fallot. Ann Thorac Surg. 2006;81:968-75.

14. Cohen MS, Anderson RH, Cohen MI, Atz AM, Fogel M, Gruber PJ, et al. Controversies, genetics, diagnostic assessment, and outcomes relating to the heterotaxy syndrome. Cardiol Young. 2007;17:29-43.

15. Hashmi A, Abu-Sulaiman R, McCrindle BW, Smallhorn JF, Williams WG, Freedom RM. Management and outcomes of right atrial isomerism: a 26-year experience. J Am Coll Cardiol. 1998;31:1120-6.

16. Gaynor JW, Collins MH, Rychik J, Gaughan JP, Spray TL. Long-term outcome of infants with single ventricle and total anomalous pulmonary venous connection. J Thorac Cardiovasc Surg. 1999;117:506-14.

17. Azakie A, Merklinger SL, Williams WG, Van Arsdell GS, Coles JG, Adatia I. Improving outcomes of the Fontan operation in children with atrial isomerism and heterotaxy syndromes. Ann Thorac Surg. 2001;72:1636-40.

18. Stamm C, Friehs I, Duebener LF, Zurakowski D, Mayer JE, Jonas RA, et al. Improving results of the modified Fontan operation in patients with heterotaxy syndrome. Ann Thorac Surg. 2002;74:1967-78.

19. Gangireddy C, Rectenwald JR, Upchurch GR, Wakefield TW, Khuri S, Henderson WG, et al. Risk factors and clinical impact of postoperative symptomatic venous thromboembolism. J Vasc Surg. 2007;45:335-42.

20. Kenet G, Strauss T, Kaplinsky C, Paret G. Hemostasis and thrombosis in critically ill children. Semin Thromb Hemost. 2008;34:451-8.

21. Thornburg CD, Smith PB, Smithwick ML, Cotten CM, Benjamin DK Jr. Association between thrombosis and bloodstream infection in neonates with peripherally inserted catheters. Thromb Res. 2008;122:782-5.

22. Li JS, Yow E, Berezny KY, Bokesch PM, Takahashi M, Graham TP, et al. Dosing of clopidogrel for platelet inhibition in infants and young children: primary results of the platelet inhibition in children on cLOpidogrel (PICOLO) trial. Circulation. 2008;117:553-9. 